\title{
Pervasive information gathering and data mining for efficient business administration
}

Journal of Vacation Marketing

$1-12$

(C) The Author(s) 2015

Reprints and permission:

sagepub.co.uk/journalsPermissions.nav DOI: $10.1177 / 13567667 / 5617219$

jvm.sagepub.com

\section{Fernando J Garrigos-Simon, Roberto Llorente and Maria Morant}

Universidad Politecnica de Valencia, Spain

Yeamduan Narangajavana

Jaume I Universitat, Spain

\begin{abstract}
Following a multidisciplinary perspective (that combines the literature from management, information systems, marketing and engineering telecommunications perspectives), the purpose of this article is to create and analyze a conceptual framework and to propose a new methodology that encompasses different techniques for pervasive information gathering in hotels and for identifying clients' habits. Focusing on the future of hotels, this work presents new technologies for hotels suitable for correlating the customers' on-site activities with online activities including passive location tracking using Wi-Fi devices' connectivity, customer satisfaction evaluated via facial or voice recognition using inbuilt cameras/microphones altogether with data mining analysis. Moreover, this article explains how multidisciplinary consumer behavior can be analyzed by data mining to include this information in the vacation marketing approach for efficient business administration.
\end{abstract}

\section{Keywords}

Consumer behavior, data mining, habit identification, marketing, new technologies, sensor networks

\section{Introduction}

From the time of its emergence, information technology (IT) has played a significant role in the tourism industry (Zhang et al., 2009: 351), and specifically in the case of hospitality. The use and management of information systems in hotels has been continuous since 1947, when the Westin hotel introduced 'Hoteltype', and teletype machines started to enable instantaneous confirmations of reservations (Bilgihan et al., 2011). Since then, advances mainly in computer reservation systems, global distribution systems, property management systems, and customer relationship management (CRM) techniques have transformed hotels' behavior (Buhalis and Law, 2008; Martinez et al., 2006).

Nowadays, the development of the World Wide Web, the Internet, the spread of social networks, and the use of Web2.0 tools (apart from the use of search engine marketing (SEM), search engine optimization (SEO), or yield and revenue management techniques) is changing the way hotels operate. However, current technologies will become insufficient and inadequate with the emergence of the called Web 3.0 or Semantic Web, and the arrival of intelligent machines and new technologies, addressed mainly to improve the relationships with customers and the environment (Garrigos-Simon et al., 2012).

The implementation of mobile communications and radio-frequency identification devices (RFID)

\footnotetext{
Corresponding author:

Fernando J Garrigos-Simon, Universidad Politecnica de Valencia, Camino Vera S/N, 7D Building, Valencia 46022, Spain.

Email: fgarrigos@doe.upv.es
} 


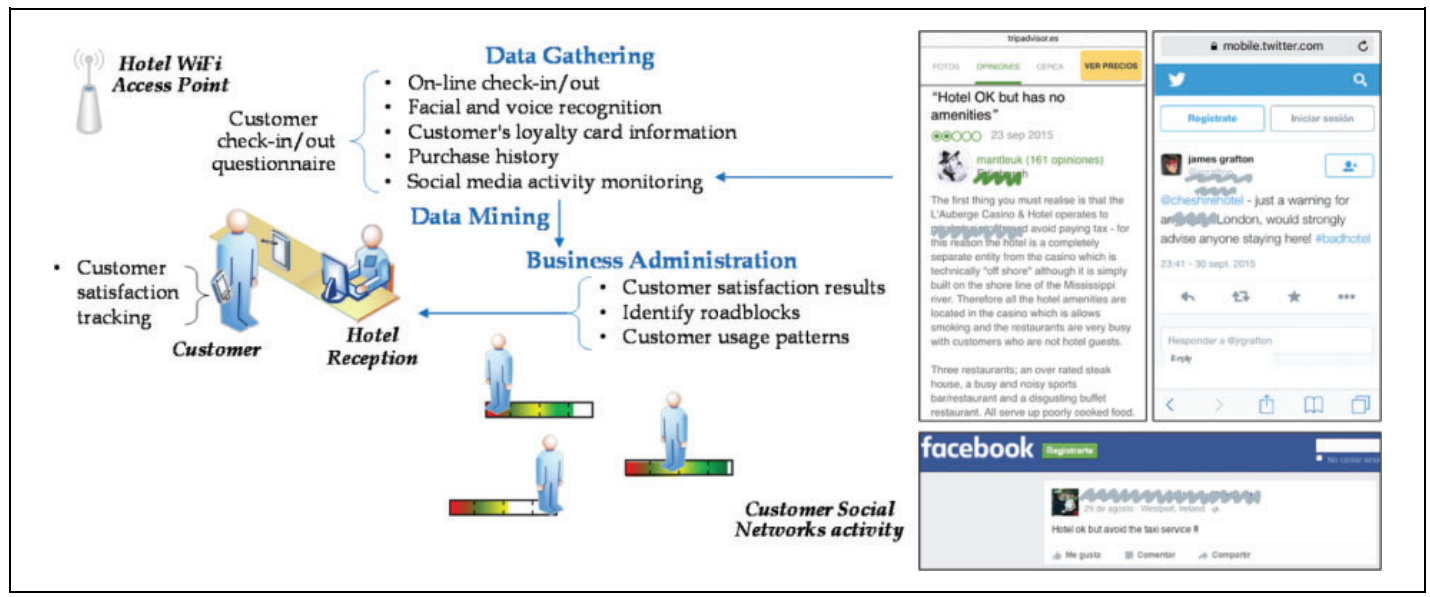

Figure I. Proposed paradigm: User activity and satisfaction is automatically monitored on-premises. Data mining identify correlation with online/social user activity like Facebook, Twitter, and TripAdvisor giving feedback to business administration.

and the use of data warehousing, data mining, database marketing, and the big data are transforming definitively the management and operation of hotels. More specifically, new technologies for tracking customer's movement using marketavailable technology devices combined with social media activity can be used to provide context-based marketing.

The new marketing of tourism organizations and destinations cannot be understood without realizing about the new transformations produced by the development of information systems, as they changed the relationship with customers. Hence, new technologies can be used in a way where the customer requirements are translated in the production of personalized services. This means a focal point in a production process based completely on a marketing perspective focused on the customer as the center and origin of the services to be offered by hotels. Together with its impact on the organization marketing, business information gathering with deep data analysis becomes a key factor for the success of modern management (Gates, 1999).

Customers' activity information can be gathered using market-available technology like context-aware smartphone applications (Meehan et al., 2013), active beacon technology based on low-energy Bluetooth as found in Apple iBeacon technology (Gast, 2014), near field communication (NFC) (Pesonen and Horsterb, 2012), and passive customer tracking based on sensing the customers' smartphone Wi-Fi signal or with straightforward RFID.

In addition to tracking on-site customers' activities, it is of utmost importance to monitor customers' satisfaction. This can be implemented by facial analysis with camera video processing.

Customer satisfaction/dissatisfaction is nowadays correlated to the customer's social media activity (via Facebook, Twitter or the like). By tracking customer satisfaction information and their usage habits, hotels can improve the customer's experience and provide personalized vacation marketing finely tailored to their guests' necessities, taking into account detailed variables such as customer mood and interest in certain activities or amenities.

This proposed paradigm is depicted in Figure 1. This approach to business management can be implemented improving the layout for customer flow with the combination of the guest location and images from cameras to gauge customer facial expression in order to offer products adequate to the mood status or correlating customer comments on social media with the guest activity at hotel premises. Nowadays, vacation marketing should take into account the consumergenerated media to recommend and announce their services as travelers increasingly rely on other customers' reviews to plan their trips (Filieria et al., 2015). Websites like TripAdvisor containing over 250 million reviews from travelers around the world and opinions expressed in the social media (e.g. Facebook, Twitter, and Instagram) have a strong influence on future travel decisions.

This article analyzes the improvements that can be achieved using new technologies and shows how hotels can copy with these improvements. In the next sections, the changes produced in hotel operations due to the emergence of these 
new technologies are analyzed. Several information management techniques are presented in this article based on pervasive information gathering and ad hoc processing to identify the client habits. The proposed pervasive information gathering oriented from the marketing perspective aims to correlate the actual on-site customer activities with their online activities. These techniques include passive location tracking, facial or voice recognition using in-building cameras/ microphones, and the analysis by data mining of multi-domain customer behavior in social media.

\section{Hotels' use of IT in the new era of marketing}

Nowadays, the development of the Internet and the spread of social networks and virtual communities have transformed the way in which hospitality enterprises operate. In the new area, the tourism and organization chains are becoming more and more digitalized (Garrigos-Simon et al., 2014). Many operations inside the hotels are being automatized and improved through the use of new and sophisticated IT systems that have transformed the management of tourism organizations (Buhalis, 2003).

In addition, the development of social networks, the emergence of the Web 3.0 or semantic web, and essentially the transformation of the role of the customers (who have more and more information and growing desires to participate in the design and production of almost all processes of the hospitality organizations) are promoting the development of sophisticated CRM, open innovations, co-creation, and crowdsourcing techniques (Buhalis and Foerste, 2015; GarrigosSimon et al., 2012; Neuhofer et al., 2015) and the use of the Masscapital (Garrigos-Simon and Narangajavana, 2014).

Thus, these emerging technologies create new opportunities for hotels, in a frame where the relevance of IT is not only important but critical for the success and survival of hospitality organizations.

In this new hospitality environment, the transformations promoted by the evolution of IT are changing the conception of the management and marketing inside and outside the hotels, and managers have to copy with these changes.

By following customers' requirements, managers in hospitality and tourism have attempted to apply also IT to improve customer services, enhance operational efficiency, and ultimately increase the revenue and profitability (Law et al., 2014).

In addition, IT has been used with diverse purposes: for the internal reengineering of hospitality firms (e.g. office systems and reservation systems), to improve management and enhance learning, knowledge, and even creativity, or specially to improve the marketing and communication with tourists.

Nowadays, diverse mechanisms are used to improve operations and other functions inside the firms. Specifically, IT tools are being used to automatize routine operations and to improve the diverse inventories in hotels, such as reservations, the management of checking-in and out, cleaning, self-service, preparation of meals, security processes, personal monitoring processes, or even diverse services to satisfy customers (Bilgihan et al., 2011; Garrigos-Simon and Narangajavana, 2006). In addition, these and other authors such as Buhalis and Law (2008) relate the essential importance of the use of IT to improve business intelligence (especially the knowledge of markets, competitors or products) as well as the management and strategy of hotels.

Although some IT applications are addressed to customers and managers, most hotel IT applications have been purely designed for employees, essentially for front of the house, back of the house or both (Bilgihan et al., 2011). However, diverse mechanisms can be implemented and used in different hotel's departments apart from the classical systems used by employees to improve operation.

Specifically, new application technologies can be implemented, focusing on the marketing area and to emphasize the relevance of applications addressed to customers, such as amenities and some self-service devices in hotels. For example, Law et al. (2014) present a review of ICT-related articles published in tourism and analyze the consumer viewpoint by looking at their role in the five stages: need recognition, information search, evaluation of alternatives, purchase decision, and post-purchase behavior.

For instance, new technologies can be used for context-based marketing in order to recognize the physical environment of their customers (Buhalis and Foerste, 2015). In addition Sigala et al. (2012) or Ge et al. (2013) emphasize the relevance of social media in tourism or its use to achieve strategic marketing goals. Furthermore, the use of self-service technologies benefits firms in terms of cost saving but also by drawing the customer into a proactive or 
coproduction role (Stockdale, 2007). In this vein, authors such as Oh et al. (2013) have analyzed why travelers choose self-service technologies over service staff and, for instance, Bilgihan et al. (2011) stress the importance of the hotels' development of online techniques or kiosks for check-in, Wi-Fi hotspots and Internet access, in-room entertainment amenities, accessible electrical outlets, guest control panels, or specific IT applications for individual customer segments (such as meetings and incentive travelers, leisure travelers, or even women). With a similar perspective, Cobanoglu et al. (2011) defined some select hotel technology amenities and empirically demonstrated the importance of 'business essentials for travelers' (business center, express check-in/check-out, in-room telephone, in-room alarm clock, and easily accessible electronic outlets), 'in-room technologies' (such as voice over Internet protocol, in-room pay-per-view, voice mail, in-room game system, in-room fitness system, and in-room universal battery charger), and 'Internet access' as predictors of hotel guest satisfaction, although they did not demonstrate the relevance of 'comfort technologies' (inroom electronic safe, in-room guest control panel, in-room personal computer, mobile access to hotel Web site, electronic wireless key card, and flat panel high-definition (HD) television) for this satisfaction.

In addition, authors such as Schrier et al. (2010) also investigated hotel in-room entertainment and showed the importance for guess of inroom movies and on-demand services.

Apart from these, Garrigos-Simon and Narangajavana (2006) stressed the relevance of IT in order to develop creativity, generate knowledge, and improve communications.

Law et al. (2014) highlighted the tremendous potential for service innovations that the creative and innovative use of technology exhibits, underlining the relevance of integrating smartphones, tablets, and other mobile and hand-held technologies in enhancing tourism experiences, pointing out the relevance of the provision of new technologies for mobile devices during trips.

Focusing on the use of mobile technologies, Hyun et al. (2009) conceptualized virtual tourism in the mobile context and provided some examples of mobile services that facilitate virtual experiences. Wang et al. (2012) analyzed the use of smartphones to obtain information to enhance tourism experience. Wendy Zhu and Morosan (2014) examined guests' adoption of interactive mobile technologies in hotels and provided suggestions to integrate these technologies based on system characteristics and users' perceptions. Neuhofer et al. (2015) concentrated on how mobile technologies can facilitate personalized experiences. These authors, apart from relating some innovative solutions of smart technology applications in tourism, concentrated in the analysis of the Happy Guest Relationship Management system and concluded stressing the critical importance of the integration of smart technologies for the creation of personalized experiences. Moreover, Minazzi and Mauri (2015) studied the effects of mobile technologies on travel habits, behaviors, and experiences, and their impact and opportunities for travel operators.

Buhalis and Law (2008) also stressed the importance of incorporating innovations such as interoperability and ontology building, the use of multimedia, the application of mobile and wireless technologies, wireless local area networks, worldwide interoperability for microwave access, Web design in both functionality and usability, or accessibility and ambient intelligence.

The relevance of ambient intelligence with the implementation of mobile communication and RFID in hospitality is also analyzed by Collins (2010) and commented by Buhalis and Law (2008), who pointed that:

this implies a seamless environment of computing, advanced networking technology and specific interfaces which should be aware of the specific characteristics of human presence and personalities; adapt to the needs of users; be capable of responding intelligently to spoken or gestured indications of desire; and even result in systems that are capable of engaging in intelligent dialogue (pp. 616-617).

Obviously, and as operative systems, we should add, apart from the development of the design and the quality of the webs the use of SEO and SEM in order to maximize efficiency in the distributions of hotels and also the use of revenue and yield management, or even dynamic price techniques (Narangajavana et al., 2014). They are used to set up prices and manage the sale and the inventory of rooms and other resources in the hotels. For instance, Pan et al. (2011) review research related to SEM in tourism, while O'Connor (2009) posit for the good use of SEM by hotels. Moreover, Law et al. (2014) stress that the new innovations (such as new technologies in virtual reality and 3-D technology), apart from 
improving operations, can also help managers to better formulate new business models and marketing strategies.

Finally, Web 2.0 advances also offer new and numerous opportunities to firms to actively engage their customers in new service development processes (Sigala, 2012). Hence, Web 2.0 applications can support activities to engage customers in all stages of new service development processes. Apart from this, Garrigos-Simon et al. (2012) stressed the relevance of the use of the semantic web or Web 3.0 tools.

The importance of these improvements is linked with the development of CRM techniques and the new marketing perspective that aims to build and strengthen long-term customer relationships (Narangajavana et al., 2014: 29). For instance, Luck and Stephenson (2009) relate relationships between CRM, technology, and concepts such as 'database marketing' to provide a better portrait of customers and their buying habits for marketing and promotional purposes.

Furthermore, Garrigos-Simon et al. (2012) emphasize broadly that in the new context of Web 3.0, intelligent machines are able to read, understand, interrelate information, and can manipulate data from cyberspace, permitting this process to be adapted by different users or firms according to their needs. As these authors postulate, in the Web 3.0 era, firms will be able to use the information gathered before, during, or after their contact with customers (via techniques such as data warehousing, data mining, or CRM) but also by using diverse pieces of information from several social networks. This perspective tries to link the management of processes outside the hotels with other inside by stressing the use of open innovation, co-working, or crowdsourcing. Obviously, these processes could not be understood without realizing about the importance of the marketing at organizations and the previously pointed change in the conception of a production process that must be conceived taking into consideration the customer as the central point of all the process.

Nevertheless and looking again for the main technological improvements used in the hotel sector, we should empathize on the fact that most of back-office applications are applications used broadly in other industries, while the rest of the systems (more adapted to the hotel industry) have been developed specifically by some enterprises; but most of them or cannot be interrelated among them, or have not being even implemented in an important part of the hospitality industry. However, the interaction of technologies inside and outside the borders of hotel firms is critical.

The analysis of big data from customer social media interaction can be used to extend the customer profile and provide personalized services (Buhalis and Foerste, 2015). A recent study in Spanish hotels pointed out that tourism companies should integrate IT in their marketing to enhance the relation between hotels, service distributors, and travel agencies (Moliner et al., 2014). In this article, we develop some technological improvements that can be used to face the marketing perspective needed in the Web 3.0 era, as they allow firms to know better the behavior of their customers and their needs.

\section{Customer passive tracking}

Location-based services and personalized offers can be provided to customers if their location is known (Benckendorff et al., 2014: 22-26). Passive Wi-Fi localization and tracking have been proposed as a relevant predictive analytics technique (Ruiz-Ruiz et al., 2014). In this approach, the customer's smartphone is set to passively search for Wi-Fi networks, which is a typical configuration for modern smartphones. Customer movements can be tracked within a fewfeet radius, even if they don't connect to a WiFi network. The customer sends a unique identification (ID) code when searching for networks, which permits the in-premises $\mathrm{Wi}-\mathrm{Fi}$ access to identify and further locate the use by triangulation (Abreu et al., 2010). In this way, it can be monitored which departments the customer uses, for how long, if a social network activity is performed, and also if the social network activity has a positive, neutral, or negative mood.

When a Wi-Fi client (phone, laptop, etc.) is looking to connect to a known network, there are two approaches it can take. The first technique, which is used by laptops and most nonsmartphone devices, involves scanning for Beacon Frames (packets broadcast by Wi-Fi routers in order to advertise their presence), waiting for a network that the client has previously connected to, and initiating a connection with it. The second technique, which is used primarily by smartphones, involves periodically broadcasting packets called Probe Requests, which contain the unique media access control address of the client and (sometimes) the name of a network to which it has previously connected. The advantage of the second technique is that by actively scanning for 


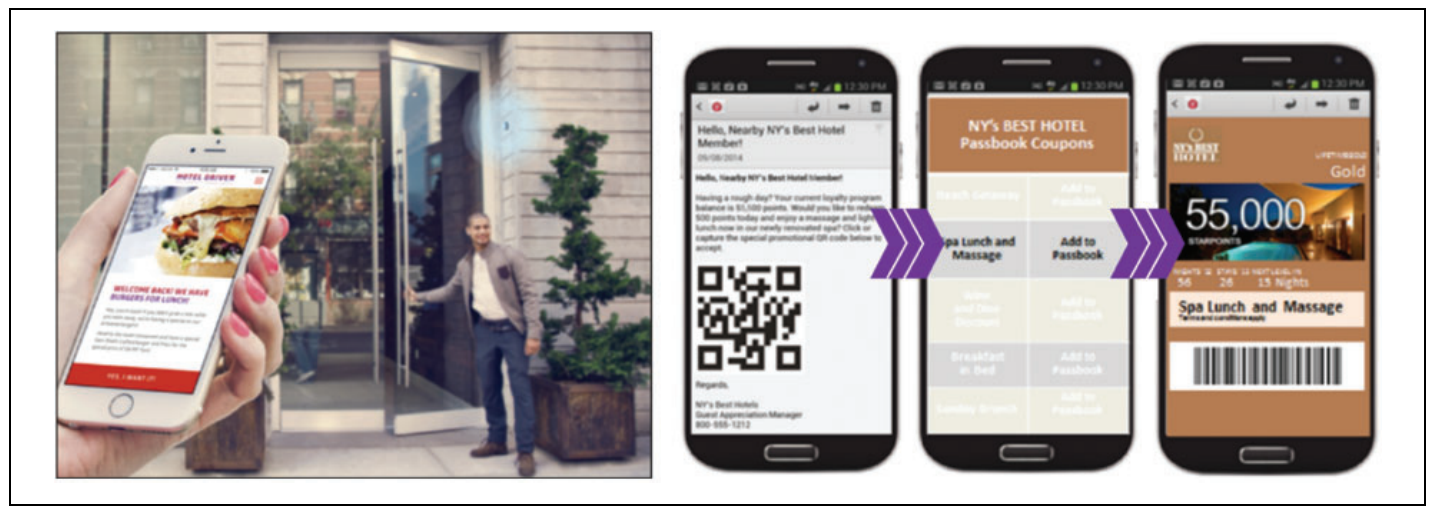

Figure 2. Customer tracking and localization for personalized services provision.

nearby routers, a phone can initiate a wireless connection faster than if it waits for the router to send out a beacon frame. While this certainly makes it more convenient to hop on a network, it also makes it possible to gather data ready for analysis.

Passive Wi-Fi tracking technology is a technique adequate to continuously locate the cell phones of the customers at the hotel premises. The tracking is completely passive for the user and is performed by the hotel Wi-Fi access points (APs). The Wi-Fi tracking permits to univocally identify each cell phone and to locate the phone during the customer activity in the premises (Musa and Eriksson, 2012). The principle of operation is based on the unique ID code sent by the device when searching for available Wi-Fi networks. This permits the in-premises APs to identify and locate the user. This process is performed without the customer's cell phone being actually connected to the network. Taking into account that a single AP can provide coverage typically in tens of meters range, the customer location resolution might not be adequate. Nevertheless, passive Wi-Fi tracking can be performed simultaneously by several APs enhancing the location by triangulation (Bumgon et al., 2011).

The application of customer location tracking in hotels has been recently adopted by several companies. For instance, GuestDriven announced in PRNewswire (2014) the application of iBeacons to the hotel industry to detect guests in the near area and send them a welcome message when they walk through the doors or special offers as depicted in Figure 2. The use of iBeacons has been extended in the last years for 'what you are close to' applications. The customers' proximity can be detected using short-range networks like Wi-Fi mentioned before or with Bluetooth low energy (e.g. iBeacon). Tourism applications include retail store enhancement, museum guidance, and map and transit assistance, between others (Gast, 2014: 6-9). Passive Wi-Fi, iBeacons, RFID, or NFC can be used to localize clients inside or near the premises and send customized offers for related services or new bookings.

Despite the passive accumulation of data could be seen as a challenge to privacy (Di Ma and Tsudik, 2010), it should be noted that the sensors don't actually follow your phone from department to department and they don't identify personal information tied to the phone's owner. Avoiding being tracked by this kind of systems is simple, but inconvenient. As long as you turn the Wi-Fi/Bluetooth radio off, the phone will stop transmitting probe requests. Obviously, from a practical perspective, manually turning Wi-Fi/Bluetooth off every time you leave your house could become quite annoying.

To avoid this, large companies like McDonald's or Starbucks are offering free Wi-Fi to its customers thus making impractical to turn the Wi-Fi radio off. For this reason, hospitalities should facilitate free $\mathrm{Wi}-\mathrm{Fi}$ connectivity to its customers in order to be able to trace the guests' activities and also be able to gather opinion information that can be exploited with data mining as depicted in the next section.

\section{Facial and voice recognition}

Facial recognition technology targets to acquire the customers' facial information as the first step for automated mood detection. Facial recognition has been enabled in the last few years by the increase in camera's resolution and the continuous upgrade in computing power in consumer electronic devices (Zhao et al., 2003). 


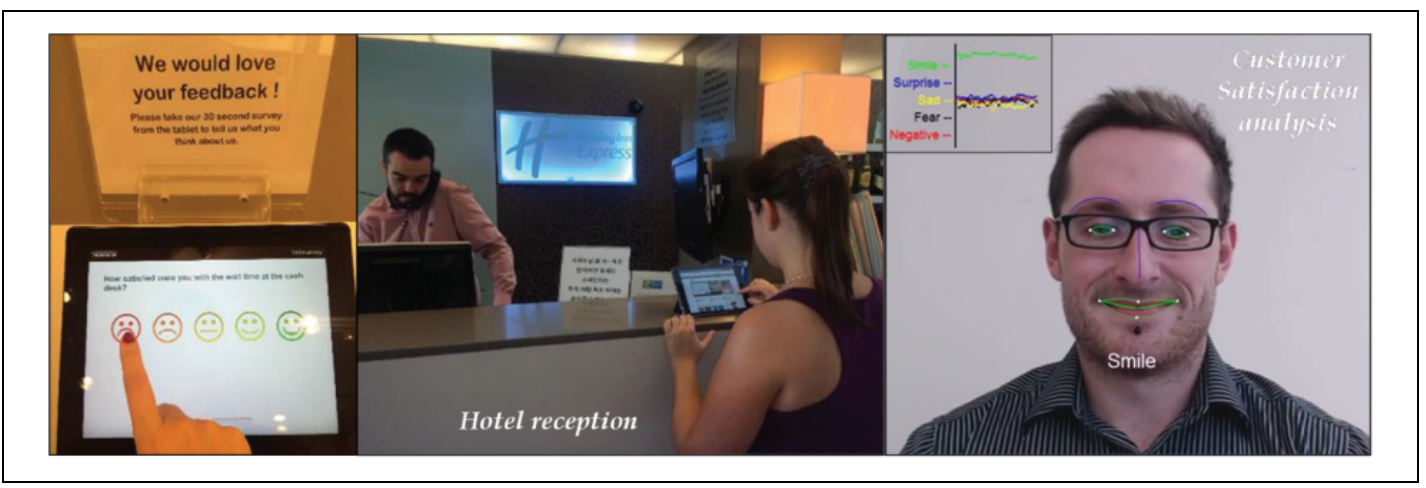

Figure 3. Customer survey and satisfaction tracking employing facial analysis applied to the future of hotels.

Facial information is usually gathered via wall-mounted HD cameras. Hotel check-in computers or tablets can also be employed for this purpose. Customer's gender, age and mood can be evaluated from the facial information (Gutta et al., 2000). Once facial information is available, the surveillance cameras can locate the customer in different places, thus effectively tracking the customer movements. Moreover, retail companies have recently started to analyze facial cues for responses to online ads and order selection screen (Kulkarni et al., 2009). Using this technology, it is possible to provide personalized marketing content according to the customer's gender, age, and mood measured by facial recognition. Figure 3 shows a test example implemented at a hotel reception using a tablet with a satisfaction survey. The in-built camera in the tablet combined with facial recognition software is able to analyze the customer's expressions. This real-time information can be combined with other data from the customer's loyalty card, such as the customer's age, purchase history, and social network activity as described previously in Figure 1. This enables effective specifically targeted offers to each customer. For example, a client with a track record of wine purchases would be attracted with a discount on a nice bottle of wine when arriving to the hotel. This 'intelligent retail technology' is currently being deployed by Synqera in Russia, Europe and the United States (Rolfe and Conroy, 2013).

In addition to facial cues identification, voice recognition can be implemented using interactive voice response (IVR). Using IVR, the customers can order services from their room via the hotel telephone directly without the necessity of involving service personnel. The IVR service is available $24 \mathrm{~h}$ and in different languages at a reduced cost. The voice calls can be processed online and extra information about the voice mood and stress can be included in the database for data mining processing. For instance, $3 \mathrm{CX}$ Hotel Module can be used for configuring hotel services such as wake-up digital receptionist and other work order requests.

\section{Multi-domain data mining}

The joint availability of RFID sensors, passive Wi-Fi/Bluetooth localization, and facial recognition in hotels or shopping environments permits to collect significant customer data in those scenarios. Different data obtained with video cameras, RFID tags, usage of credit cards, and social media are combined to extract gathered information.

The joint availability of RFID activity information, passive Wi-Fi/Bluetooth localization, facial recognition, and Internet social media interaction (e.g. Facebook and Twitter) opens up the possibility of gathering pervasive customer information during its in-premises stay and after checkout in the following weeks. Ad hoc data mining is required to extract detailed information on the key aspects influencing the customer satisfaction and the willingness to share and recommend.

Data mining processing can be configured to identify useful patterns among the customer profile. Process data mining (PDM) is defined as the algorithms used for transforming raw data in useful information that could be employed by the management to take corrective actions and maximize customer satisfaction. Data mining addresses deep information analysis by algorithmic processing to find patterns. Large and medium companies use data mining to sweep through databases and customer feedback in order to adapt their business plans. Readily examples can be found in supermarkets where 


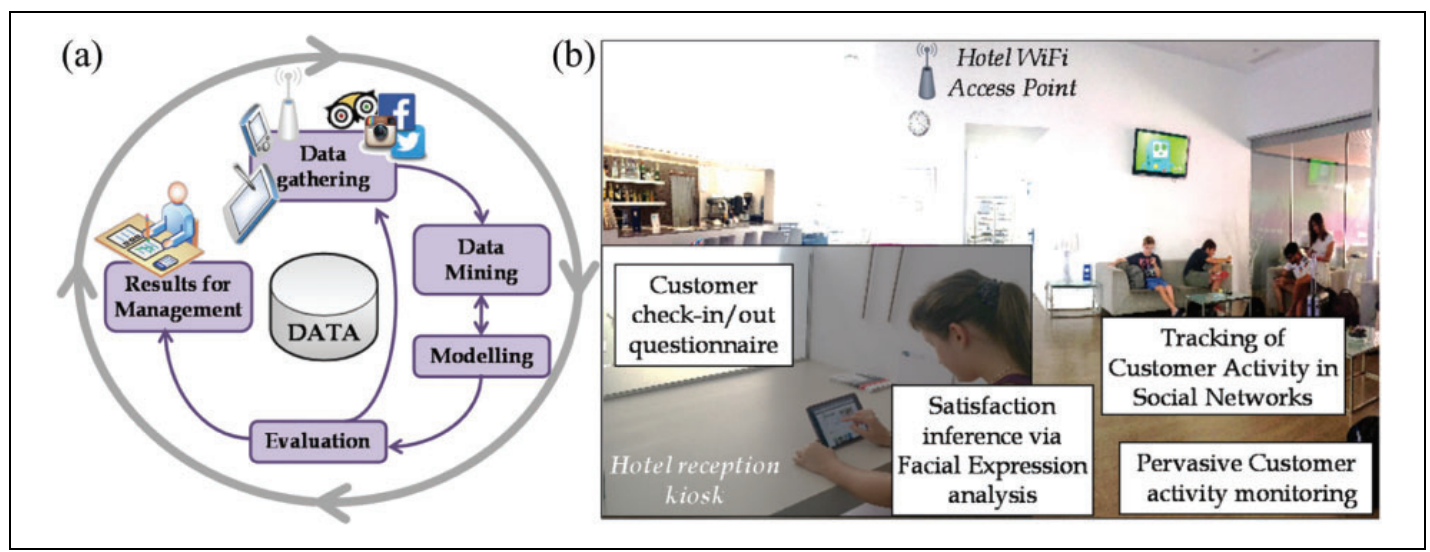

Figure 4. (a) Data mining structure for efficient business administration adapted from Chapman et al. (1999) including social media interaction, online and on-site activity tracking and (b) hotel implementation example.

data mining is used in order to figure out which of their products sells best and where in order to decide the best product placement. This can be also applied to opinion mining from hotel reviews (Raut and Londhe, 2014).

With the proper data mining of the hotel information, we can remove the management roadblocks about the customer's actual level of satisfaction or dissatisfaction, which is not always verbalized or written in the customer satisfaction forms. In this scenario, data mining pinpoints to the customer relationship key factors and permits the accurate identification of customer satisfaction. The customer analytics can be shared and compared between the different hotels in a given chain.

Data mining addresses data analysis of the pervasive information gathered from the customer in the hotel by algorithmic processing in information systems in order to find patterns, regularities, or irregularities in recurrent very large information (Rajaraman and Ullman, 2011). These patterns permit to identify the key processes the hotel management must pay special attention. Further use of data mining in large and medium hotel chains automatically process the customer feedback to gauge the success of the business plan in place (Blumberg et al., 2008).

Figure 1 depicts the process of applying process data mining on the data obtained from customer interaction with the hotel systems complemented with social network integration. The main objective is to identify the customer's usage pattern and its relationship with customer satisfaction expressed in social networks in an automatic way, that is, without the need of specific personals evaluating social networks activity.
As conventional data mining processes, several steps should be performed for PDM analysis according to Chapman et al. (1999). In Llorente and Morant (2009), data mining was proposed for higher education environment. In education, data mining can be applied to identify recurrent patterns affecting the student learning performance (Llorente and Morant, 2011). In order to adapt this analysis to the future of hotels, the specification of each scenario should be taken into account in order to provide an overview of the different services provided by the hotel and the information gathered by the customer location and the satisfaction level obtained by facial/vocal recognition or extracted from the social media activity. The steps of the data mining process can be summarized as:

1. Data preprocessing: In this phase, the data to be studied are processed before being analyzed. Usually it consists of gathering customer social information and matching public information with the information gathered from the hotel activity. In this step, the different data gathered from each customer including services used, customer tracking, facial and voice analysis results, and social media activity are prepared for data mining as depicted in Figure 4(a). Data cleaning and disambiguating methods (Khoussainova et al., 2008) should be applied to handle inconsistent data and missing values.

2. Data processing and modelling: The data are processed performing correlations in time to identify associations in the hotel information gathered (space and time) 
and the customer social activity. Frequency pattern mining analysis should be applied at this stage in order to identify recurrent factors affecting the customer perception such as a problem with a given service or personnel or in certain time frames.

3. Evaluation: In this stage, the metric is evaluated using decision tree and decision rule induction. Linear or nonlinear models can be implemented for classification. This phase comprises the customer activity profiling, data aggregation from other hotels in the chain, and comparative reporting to management. In this phase, management staff decides about the processes to be analyzed in detail.

4. Visualization of the results: The data mining results must be presented in a readable form to the hotel management. It is important to give feedback to the management on the identified patterns pointing out when and where customer dissatisfaction has been detected, so management can implement corrective actions to solve the problem. As commented before in the evaluation phase, these results can be compared with other hotels in the chain to have more feedback about the services available and their impact on the market.

The information gathered during the process is stored and following data mining analysis will benefit from the information of the previous ones. The phase sequence shown in Figure 4(a) is not strict. The arrows indicate the most important and frequent dependencies between the phases. Moving back and forth between different phases can be done if required. The life cycle of a data mining process is based on a modification of the cross-industry standard process for data mining. The outer circle in Figure 4(a) represents the cyclic nature of data mining itself.

\section{Information bits and pattern identification}

The special importance of the proposed technique is that data mining is done at the hotel premises level and also at the customer level, which permits the proper correlation of places, activity, and social interaction provided the proper individual bits of information are gathered.
We could say that the technique is based on relationship mining, the main goal of which is to discover whether there are relationships between variables in the data set saved containing a large number of bits of information. In this way, we try to find out which variables are most strongly associated with a single variable of particular interest to identify the strongest relationships between them.

Sequential pattern mining is interesting too. In this case, the objective is to find temporal associations between events, for example to determine which kind of customer behaviors lead to an eventual event or result.

The procedure for gathering the location and activity data is, naturally, the integration of WiFi/Bluetooth tracking, RFID, facial recognition, and social media activity. Usually the computer is the responsible for finding the patterns by identifying the underlying rules and features in the data. In this case, data mining is applied over a large set of variables that are tracked during the stay of the customer at the hotel.

In Figure 4(b), it is shown the application of these concepts where a tablet-mounted kiosk can be employed to gather information about the services the customer has used during his/her stay and satisfaction level. This information can be correlated with the customer activity in social media to obtain information about his/her satisfaction or satisfaction right after using a service of the hotel by analyzing the photos uploaded on Facebook or Instagram, the comments written in Twitter, or the critics included in TripAdvisor.

\section{Conclusion}

Nowadays marketing of business and tourism destinations, and specifically the vacation marketing, could not be conceived without understanding the change in the conception of the current marketing, and without knowing the impact that the new technological improvements can have for improving customers' satisfaction. This article concentrates in this point, analyzing the main technological improvements being used by hotels and explaining the main new changes that the conception of marketing and the evolution of the Web 3.0 are bringing to the hospitality industry.

This article proposes a holistic approach that encompasses different techniques for pervasive information gathering in hotels useful for identifying clients' habits and customer-usage patterns. Focusing on the future of hotels, new 
technologies were reviewed in this work to enable passive location tracking using Wi-Fi/ Bluetooth connectivity, facial recognition using in-built device cameras, voice recognition using IVR service from the hotel's telephone and data analysis. Multidisciplinary consumer behavior can be analyzed by data mining to include this information in the vacation marketing approach for efficient business administration. Different data gathered by video cameras, RFID tags, usage of credit cards, and social media can be analyzed to extract patterns and relations.

Due to the benefits of the data mining, information that can be extracted from the correlation of the on-site and online customer activities, the Future of Hotels should facilitate online Wi-Fi connectivity to their guests in order to be able to automatically track their online activities and opinions. This information can be extremely useful to obtain instantaneous information of the customer satisfaction level as they share their opinion on social media, only at the reduced cost of providing free Wi-Fi to their guests. Otherwise it would be much more difficult, even impossible, to track the social media activity of the customers when they leave the premises or finish their vacations.

Combining these new technologies, future hotels will be able to identify the customer's usage pattern and obtain the actual customer satisfaction.

\section{Declaration of Conflicting Interests}

The author(s) declared no potential conflicts of interest with respect to the research, authorship, and/or publication of this article.

\section{Funding}

The author(s) disclosed receipt of the following financial support for the research, authorship, and/or publication of this article: This research work was supported by Universitat Politècnica de València 10.13039/501100004233 PAID10-14.

\section{References}

Abreu P, Vinhas V, Mendes P, et al. (2010) Real-time wireless location and tracking system with motion pattern detection. In: Yussof H (ed.) Robot Localization and Map Building. Croatia: Intech, pp. 467-492.

Benckendorff PJ, Sheldon PJ, and Fesenmaier DR (2014) Tourism Information Technology. United Kingdom: CABI Tourism Texts.
Bilgihan A, Okumus F, Nusair K, et al. (2011) Information technology applications and competitive advantage in hotel companies. Journal of Hospitality and Tourism Technology 2(2): 139-154.

Blumberg B, Cooper DR, and Schindler PS (2008) Business Research Methods. Berkshire: McGrawHill.

Buhalis D (2003) eTourism: Information Technology for Strategic Tourism Management. Pearson Education.

Buhalis D and Law R (2008) Progress in information technology and tourism management: 20 years on and 10 years after the Internet - The state of eTourism research. Tourism Management 29(4): 609-623.

Buhalis D and Foerste M (2015, in press) SoCoMo marketing for travel and tourism: empowering co-creation of value. Journal of Destination Marketing \& Management: 1-11. http://dx.doi.org/10. 1016/j.jdmm.2015.04.001

Bumgon K, Wonsun B, and Kim YC (2011) Indoor localization for Wi-Fi devices by crossmonitoring AP and weighted triangulation. In: Proceedings of Consumer Communications and Networking Conference (CCNC), 9-12 January 2011, pp. 933-936. Las Vegas, NV: IEEE.

Chapman P, Clinton J, Kerber R, et al. (1999) CRISPDM 1.0. Step-by-step Data Mining Guide. SPSS CRISP-DM Consortium. USA: SPSS Inc.

Cobanoglu C, Berezina K, Kasavana ML, et al. (2011) The impact of technology amenities on hotel guest overall satisfaction. Journal of Quality Assurance in Hospitality \& Tourism 12(4): 272-288.

Collins G (2010) Usable mobile ambient intelligent solutions for hospitality customers. Journal of Information Technology Impact 10(1): 45-54.

Di Ma and Tsudik G. (2010) Security and privacy in emerging wireless networks. IEEE Wireless Communications 17(5): 12-21.

Filieria R, Alguezauib S, and McLeaya F (2015) Why do travelers trust TripAdvisor? Antecedents of trust towards consumer-generated media and its influence on recommendation adoption and word of mouth. Tourism Management 51: 174-185.

Garrigos-Simon FJ, Alcami RL, and Ribera TB (2012) Social networks and Web 3.0: their impact on the management and marketing of organizations. Management Decision 50(10): 1880-1890.

Garrigos-Simon FJ and Narangajavana Y (2006) Capacidades Directivas y Nuevas Tecnologías en el Sector Turístico. Castellon: Publicaciones de la Universitat Jaime I.

Garrigos-Simon FJ, Narangajavana Y, and GaldónSalvador JL (2014) Crowdsourcing as a competitive advantage for new business models. In: 
GilPechuán I, Palacios-Marqués D and PerisOrtiz MP (eds) Strategies in E-Business. New York, NY: Springer, pp. 29-37.

Garrigos-Simon FJ and Narangajavana Y (2014) The use of masscapital in education. In: Garrigos F, et al. (ed.) INNODOCT/14 "Strategies for Education in a New Context". Valencia: Universidad Politécnica de Valencia, pp. 19-29.

Gates B (1999) Business @ the Speed of Thought. Pearson Education, Penguin Books. Essex, UK: Pearson Education Limited, Pearson Longman.

Gast MS (2014) Building Applications with iBeacon: Proximity and Location Services wih Bluetooth Low Energy. Sebastopol, CA: O'Reilly Media.

Ge J, Gretzel U, and Clarke RJ (2013) Strategic use of social media affordances for marketing: a case study of Chinese DMOs. In: Xiang Z and Tussyadiah I (eds) Information and Communication Technologies in Tourism 2014. Dublin: Springer International Publishing, pp. 159-173.

Gutta S, Huang JRJ, Jonathon P, et al. (2000) Mixture of experts for classification of gender, ethnic origin, and pose of human faces. IEEE Transactions on Neural Networks 11(4): 948-960.

Hyun MY, Lee S, and Hu C (2009) Mobile-mediated virtual experience in tourism: concept, typology and applications. Journal of Vacation Marketing 15(2): 149-164.

Khoussainova N, Balazinska M, and Suciu D (2008) Probabilistic event extraction from RFID data. In: Proceedings of the 24th International Conference on Data Engineering (ICDE). IEEE, pp. $1480-1482$.

Kulkarni SS, Reddy NP, and Hariharan SI (2009) Facial expression (mood) recognition from facial images using committee neural networks. Biomedical Engineering OnLine 8: 16.

Law R, Buhalis D, and Cobanoglu C (2014) Progress on information and communication technologies in hospitality and tourism. International Journal of Contemporary Hospitality Management 26(5): $727-750$.

Llorente R and Morant M (2009) Accurate knowledge evaluation by deep data-mining in telecommunication engineering studies. In: Proceedings of 20th Annual Conference Innovation in Education for Electrical and Information Engineering (EIE), 22-24 June, Valencia, Spain. IEEE.

Llorente R and Morant M (2011) Data mining in higher education In: Funatsu $\mathrm{K}$ and Hasegawa $\mathrm{K}$ (eds) New Fundamental Technologies in Data Mining, 22-24 June, pp. 201-220. Valencia, Spain Rijeka: Intech.

Luck D and Stephenson ML (2009) An evaluation of the significant elements of customer relationship management within the hotel industry. Tourism Today 9: 7-26.

Martınez J, Majo J, and Casadesus M (2006) El uso de las tecnologias de la informacion en el sector hotelero. In: Actas del VI Congreso Turismo y Tecnologías de la Información y las Comunicaciones, Turitec 2006 Proceedings, 18-20 October 2006, Malaga, Spain.

Meehan K, Lunney T, Curran K, et al. (2013) Contextaware intelligent recommendation system for tourism. In: Proceedings of 2013 IEEE International Conference on Pervasive Computing and Communications Workshops (PERCOM Workshops), 18-22 March 2013, pp. 328-331. San Diego, CA: IEEE.

Minazzi R and Mauri AG (2015) Mobile technologies effects on travel behaviours and experiences: a preliminary analysis. In: Tussyadiah I and Inversini A (eds) Information and Communication Technologies in Tourism 2015. Switzerland: Springer International Publishing, pp. 507-521.

Moliner B, Fuentes M, and Gil I (2014) ICT as the basis for segmentation in the context of tourism B2B: applied study in Spanish hotels. Revista de Análisis Turístico 18: 19-31.

Musa ABM and Eriksson J (2012) Tracking unmodified smartphones using Wi-Fi monitors. In: Proceedings of the 10th ACM Conference on Embedded Network Sensor Systems (SenSys '12), 6-9 November 2012, Toronto, Canada, pp. 281-294. New York, NY: ACM.

Narangajavana Y, Garrigos-Simon FJ, García JS, et al. (2014) Prices, prices and prices: a study in the airline sector. Tourism Management 41: 28-42.

Neuhofer B, Buhalis D, and Ladkin A (2015) Smart technologies for personalized experiences: a case study in the hospitality domain. Electronic Markets 25: 243-254.

O'Connor P (2009) Pay-per-click search engine advertising: are hotel trademarks being abused? Cornell Hospitality Quarterly 50(2): 232-244.

Oh H, Jeong M, and Baloglu S (2013) Tourists' adoption of self-service technologies at resort hotels. Journal of Business Research 66(6): 692-699.

Pan B, Xiang Z, Law R, et al. (2011) The dynamics of search engine marketing for tourist destinations. Journal of Travel Research 50(4): 365-377.

Pesonen J and Horsterb E (2012) Near field communication technology in tourism. Tourism Management Perspectives 4: 11-18.

PRNewswire (2014) GuestDriven and Estimote deliver iBeacon technology to Hotel industry. PR Newswire Association LLC. Available at: http:// 
www.prnewswire.com/news-releases/guestdrivenand-estimote-deliver-ibeacon-technology-to-hotelindustry-300004646.html (accessed 8 October 2015).

Rajaraman A and Ullman JD (2011) Mining of Massive Datasets. New York: Cambridge University Press.

Raut VB and Londhe DD (2014) Opinion mining and summarization of hotel reviews. In: Guerrero J E (ed.) Proceedings of International Conference on Computational Intelligence and Communication Networks (CICN), 14-16 November 2014, Bhopal, India, pp. 556-559. Piscataway, NJ: IEEE.

Rolfe E and Conroy V (eds) (2013) Handpoint releases open source code for mPOS. Payments Cards and Mobile 5(4): 28.

Ruiz-Ruiz AJ, Blunck H, Prentow TS, et al. (2014) Analysis methods for extracting knowledge from large-scale WiFi monitoring to inform building facility planning. In: Proceedings International Conference on Pervasive Computing and Communications, Budapest, Hungary, 24-28 March 2014, pp. 130-138. Piscataway, NJ: IEEE.

Schrier T, Erdem M, and Brewer P (2010) Merging task-technology fit and technology acceptance models to assess guest empowerment technology usage in hotels. Journal of Hospitality and Tourism Technology 1(3): 201-217.
Sigala M (2012) Web 2.0 and customer involvement in new service development: a framework, cases and implications in tourism. In: Sigala (ed) Social Media in Travel, Tourism and Hospitality: Theory, Practice and Cases. Farnham: Ashgate Publishing, Ltd, pp. 25-33.

Sigala M, Christou E, and Gretzel U (eds) (2012) Social Media in Travel, Tourism and Hospitality: Theory, Practice and Cases. Farnham: Ashgate Publishing, Ltd.

Stockdale R (2007) Managing customer relationships in the self-service environment of e-tourism. Journal of Vacation Marketing 13(3): 205-219.

Wang D, Park S, and Fesenmaier DR (2012) The role of smartphones in mediating the touristic experience. Journal of Travel Research 51(4): 371-387.

Wendy Zhu W and Morosan C (2014) An empirical examination of guests' adoption of interactive mobile technologies in hotels: revisiting cognitive absorption, playfulness, and security. Journal of Hospitality and Tourism Technology 5(1): 78-94.

Zhang X, Song H, and Huang GQ (2009) Tourism supply chain management: a new research agenda. Tourism Management 30(3): 345-358.

Zhao W, Chellappa R, Phillips P, et al. (2003) Face recognition: a literature survey. ACM Computing Surveys 35(4): 399-458. 